\section{T time for tumors}

\section{By Lev Osherovich, Senior Writer}

No therapeutic cancer vaccine has yet shown sufficient efficacy to be approved in the U.S., in part because of the complex immune response to vaccination. A study in Cancer Cell helps refine the tactics for developing pancreatic cancer vaccines, showing that local activity by tumor-seeking helper T cells can retard-or promote-tumor development. ${ }^{1}$

The study, conducted by a team led by Martin Röcken, professor of dermatology at Eberhard Karls University, could help cancer vaccine makers design therapies that direct $\mathrm{T}$ cells to the right place and elicit the right kind of immune response.

The group used an established mouse model in which overexpression of a viral oncoprotein called $\mathrm{T}$ antigen (TAG) promotes islet cell adenomas and, eventually, carcinomas in the pancreas. ${ }^{2}$ Such tumors develop extensive vascular structures that facilitate tumor growth.

The researchers raised helper $\mathrm{T}$ cells that recognized a TAG fragment in cell culture. The T cells were labeled with a fluorescent dye and injected into mice. Within days, the TAG-seeking $\mathrm{T}$ cells migrated to pancreatic lymph nodes in TAG-expressing mice but not in wild-type controls.

Once on the scene, the $\mathrm{T}$ cells prevented both the appearance of new tumors and the expansion of existing ones beyond the adenoma stage.

Compared with mock-treated controls, mice that received TAG-specific $\mathrm{T}$ cell transfusions had fewer and smaller pancreatic tumors with less extensive vascularization.

$\mathrm{T}$ cell-treated mice, including those treated after tumors started to form, lived longer than mock-treated controls.

"We show that T cells can induce tumor dormancy," Röcken told SciBX.

\section{Playing TAG with tumors}

According to conventional wisdom, helper $\mathrm{T}$ cells act indirectly in cancer vaccines by secreting cytokines that prompt cytotoxic $\mathrm{T}$ cells to attack tumors. This principle is the basis of several therapeutic cancer vaccines. ${ }^{3}$

However, Röcken's team found that mice lacking most of their cytotoxic T cells still could benefit from TAG-specific helper T cells. Although the pancreatic tumors of these $\mathrm{T}$ cell-treated mice showed no signs of apoptosis, which would be indicative of cytotoxic $\mathrm{T}$ cell attack, the researchers did see a decrease in the pancreatic incorporation of bromodeoxyuridine (BrdU) compared with that seen in wild-type controls. BrdU labels newly replicated DNA in proliferating tumors.
Thus, the helper T cell-based treatment did not kill tumor cells but, instead, arrested their growth.

Röcken's team next asked how proinflammatory cytokines such as interferon- $\gamma($ IFN- $\gamma)$ influence homing and tumor restriction by TAGspecific T cells. ${ }^{4}$ In mice depleted of IFN- $\gamma$, Röcken's team found that T cells still migrated to the pancreas, but they promoted tumor growth instead of preventing it. IFN- $\gamma$-depleted mice that received tumortargeting $\mathrm{T}$ cells had larger and more highly vascularized tumors than untreated IFN- $\gamma$-depleted mice.

The team got similar results in mice lacking tumor necrosis factor receptor 1 (TNFR1), a target of the inflammatory cytokine tumor necrosis factor- $\alpha$ (TNF- $\alpha$ ). Even without added T cells, TNFR1 mutation shortened the survival of TAG-expressing mice compared with that of wild-type controls. TNFR1-deficient mice that received T cell therapy had even bigger tumors with more extensive BrdU incorporation and did not survive as long as untreated controls.

These findings suggest that in the absence of TNF signaling, T cells exacerbate cancer progression.

\section{Fine lines}

Röcken told SciBX that the study illustrates the fine line between help and harm in cancer vaccine development.

"If you have the right combination of cytokines, it works, but if you generate the wrong cytokine pattern, $T$ cells can actually enhance tumor growth," he said.

Röcken noted that TNFR1 experiments show that the outcome of $\mathrm{T}$ cell treatment is influenced by at least three types of cells: the $\mathrm{T}$ cells themselves, the tumor cells and the surrounding noncancerous cells that develop into vascular tissue in response to signals from tumor cells.

In the TNFR1 mutants, "the T cells are still functioning normally," said Röcken. "The defect is in the microenvironment or in the tumor itself," although the precise cells responding to TNF signaling remain unknown.

Ruth Ganss, associate professor at the Western Australian Institute for Medical Research, told $S c i B X$ that the study reveals many new questions about which cells mediate the IFN- $\gamma$ and TNF- $\alpha$ effects and how vasculogenic cells in the tumor environment respond to nearby $\mathrm{T}$ cells.

Another outstanding question is whether $\mathrm{T}$ cells change their portfolio of cytokines when exposed to a tumor microenvironment. Röcken told SciBX that in the absence of IFN- $\gamma$ and TNFR1, the Thelper type 1 (Th1) cells used in the study may behave more like Thelper type 2 (Th2) cells.

Th2 cells have been associated with negative outcomes in cancer vaccine trials, perhaps because of an altered balance of pro- and anti-inflammatory cytokines. ${ }^{5}$

Zena Werb, a professor of anatomy at the University of California, San Francisco, told SciBX that the experiments with IFN- $\gamma$ suggest that immune cells in the surrounding microenvironment, such as macrophages, are critical for $\mathrm{T}$ cell control of tumors. 


\section{TARGETS \& MECHANISMS}

"It is already known that interferon- $\gamma$ or interferon- $\gamma$-producing $\mathrm{T}$ cells protect against malignancies," said Werb. "This study explains how and also shows that it can be subverted."

Werb suggested that the next step would be to administer IFN- $\gamma$ or "short treatments of TNF" to tumor sites to see if these cytokines are sufficient to suppress tumor growth.

Along these lines, Röcken cited evidence that IFN- $\gamma$ and TNFR1 have been shown to work together to suppress tumor growth in a mouse model of spleen cancer. ${ }^{6}$ However, both Röcken and Robert Burns, CEO of Immunox Inc., noted that neither IFN- $\gamma$ nor TNF- $\alpha$ monotherapy has been especially successful in cancer trials.

Indeed, Ganss told SciBX that "since dosing and timing of cytokines is so critical, it will be difficult to design a cytokine therapy that can mimic the complex immune response described in the Cancer Cell paper."

\section{T trials}

Burns said the Röcken study illustrates that inflammatory cytokines such as IFN- $\gamma$ and TNF- $\alpha$ are needed to prime the immune response to tumors and thus could be important elements of vaccine adjuvant strategies.

Immunox is developing adjuvants for therapeutic and prophylactic vaccines. Burns was formerly CEO of cancer vaccine company Celldex Therapeutics Inc., now part of Avant Immunotherapeutics Inc.

"We know that the immune system struggles to recognize a tumor in the absence of some sort of alerting signal," said Burns. Without inflammatory cytokines, "the alternative could be a sort of subversion" of normal immunological activity by the tumors, leading to enhanced tumor growth.

Burns cautioned that differences in the immunological behavior of mouse and human tumors make it difficult to predict whether the Röcken study will be helpful in developing cancer vaccines.

Kristen Hege, VP of clinical research at cancer vaccine company Cell Genesys Inc., said that Röcken's study provides a new model for probing interactions between the immune system and tumor microenvironment in angiogenesis.

"This area has been historically underappreciated," she said.
Hege said that although previous studies suggested that therapeutic vaccines could promote tumor dormancy, this study provides the first mechanistic insights into the process.

The findings also increase the toolbox of immunological tricks that can be deployed by cancer vaccines.

Early cancer vaccine strategies used helper $\mathrm{T}$ cell responses primarily for "regulating or optimizing a cytotoxic T cell response" Hege noted. The Röcken study "raises in my mind the possibility of combining immunotherapy with antiangiogenic effects" mediated by IFN- $\gamma$ or other helper T cell-derived cytokines.

Cell Genesys uses its GVAX cancer vaccine platform to target a range of tumor types. The company's lead vaccine for prostate cancer consists of irradiated tumor cells supplemented with granulocyte/macrophage colony-stimulating factor (GM-CSF), a dendritic cell adjuvant that enhances acquired immunity to tumor factors. ${ }^{7}$

GVAX vaccine for prostate cancer is in Phase III trials. GVAX vaccine for pancreatic cancer is in Phase II trials.

Röcken said the work in this study was not patented, but that he was "open to working with industry" to further develop the technology.

\section{REFERENCES}

1. Müller-Hermelink, N. et al. Cancer Cell; published online June 9, 2008; doi:10.1016/j.ccr.2008.04.001

Contact: Martin Röcken, Eberhard Karls University,

Tübingen, Germany

e-mail: mrocken@med.uni-tuebingen.de

2. Casanovas, O. et al. Oncogene 24, 6597-6604 (2005)

3. Bernstein, K. BioCentury 14(24), A7-A14; May 29, 2006

4. Wu, T.H. et al. J. Immunol. 172, 3243-3251 (2004)

5. Coussens, L.M. \& Werb, Z. Nature 420, 860-867 (2002)

6. Zhang, B. et al. J. Clin. Invest. 118, 1398-1404 (2008)

7. Bouchie, A. BioCentury 16(16), A21; April 7, 2008

\section{COMPANIES \& INSTITUTIONS MENTIONED}

Avant Immunotherapeutics Inc. (NASDAQ:AVAN), Needham, Mass. Cell Genesys Inc. (NASDAQ:CEGE), South San Francisco, Calif. Eberhard Karls University, Tübingen, Germany Immunox Ltd., Oxford, U.K.

University of California, San Francisco, Calif. Western Australian Institute for Medical Research, UWA Centre for Medical Research, Perth, Australia 